\section{Effective and underprescribed: what about clozapine?}

Helge H. O. Müller

\section{Department of Psychiatry, Carl von Ossietzky University Oldenburg, Germany}

Clinical psychiatry, especially pharmacological-based treatment regimens still face the problem of high rates of partial or non-responders to the various treatment strategies. So in schizophrenia, a serious psychiatric disease with regard to overall impairment of patients up to three-quarters will experience a relapse after their first episode and one-fifth is facing long-term symptoms often leading to disability and dramatically reduced quality of life and psychosocial outcome. ${ }^{1-3}$

Solid evidence suggests that Clozapine is the most effective antipsychotic drug for schizophrenics who do not respond to treatment with first- or second-generation antipsychotics. ${ }^{4}$ So approximately $60 \%$ of those who are considered treatment-resistant will respond to clozapine and its clinical use is supported by studies with various designs showing the positive outcomes and reduced hospitalization rates. ${ }^{5,6}$ In addition to its utility in schizophrenia, accumulating evidence supports clozapine's utility for a variety of other disorders and psychopathologic symptoms, such as hostility and aggression. ${ }^{7}$ There is also solid evidence in other psychiatric and neuropsychiatric diseases like treatment-resistant bipolar disorder, ${ }^{8}$ Lewy body dementia psychosis ${ }^{9}$ and psychosis in borderline personality disorder. ${ }^{10}$ The work of Wahid et al. published in Mental Illness, Volume 9, Issue 2 (2017), contributes to that bride indication implications of clozapine use. ${ }^{11}$

Having that positive evidence in mind there still is a dark side in the clinical use. Because of the sometimes serious somatic side effects of clozapine like myocarditis, cardiomyopathy, seizures and especially the severe neutropenia risk the Federal Food and Drug Administration mandated the monitoring of blood draws when using clozapine. That is likely one main reason that the use of clozapine in the US has been steadily declining. 12

Knowing all antipsychotic medication strategies to have potentially serious side effects and looking at the overall reduced survival rates of schizophrenics the (in most cases good to manage) clinical use of clozapine should stay in mind of every prescriber facing the challenges in treatment of schizophrenic and psychotic-associated diseases.

\section{References}

1. Owen MJ, Sawa A, Mortensen PB. Schizophrenia. Lancet. 2016;388:8697.

2. Campellone TR, Sanchez AH, Kring AM. Defeatist performance beliefs, negative symptoms, and functional outcome in schizophrenia: a meta-analytic review. Schizophr Bull 2016;42:134352.

3. Luciano A, Bond GR, Drake RE. Does employment alter the course and outcome of schizophrenia and other severe mental illnesses? A systematic review of longitudinal research. Schizophr Res 2014;159:312-21.

4. Warnez S, Alessi-Severini S. Clozapine: a review of clinical practice guidelines and prescribing trends. BMC Psychiatry 2014; $14: 102$

5. Lieberman JA, Stroup TS, McEvoy JP, et al. Effectiveness of antipsychotic drugs in patients with chronic schizophrenia. N Engl J Med 2005;353:120923

6. Samara MT, Dold M, Gianatsi M, et al. Efficacy, acceptability, and tolerability of antipsychotics in treatment-resistant schizophrenia: a network meta-analysis. JAMA Psychiatry 2016;73:199-210.

7. Victoroff J, Coburn K, Reeve A, et al. Pharmacological management of persistent hostility and aggression in per-
Corresponence: Helge H.O. Müller, Department of Psychiatry, Carl von Ossietzky University Oldenburg, Hermann-Ehlersstrasse 7, D-26160 Bad Zwischenahn, Germany. Tel.: +49.441.9615.1507 - Fax: +49.441.9615.1599 E-mail: helge.mueller1@uni-oldenburg.de

Key words: schizophrenia; clozapine

Conflict of interest: the author declares no potential conflict of interest.

Received for publication: 21 April 2017. Accepted for publication: 18 May 2017.

This work is licensed under a Creative Commons Attribution-NonCommercial 4.0 International License (CC BY-NC 4.0).

(C) Copyright H.H. O. Müller, 2017

Licensee PAGEPress, Italy

Mental Illness 2017: 9:7193

doi:10.4081/mi.2017.7193

sons with schizophrenia spectrum disorders: a systematic review. J Neuropsychiatry Clin Neurosci 2014;26:283-312.

8. Li XB, Tang YL, Wang CY, de Leon J. Clozapine for treatment-resistant bipolar disorder: a systematic review. Bipolar Disord 2015;17:235-47.

9. Borek LL, Friedman JH. Treating psychosis in movement disorder patients: a review. Expert Opin Pharmacother 2014;15:1553-64.

10. Beri A, Boydell J. Clozapine in borderline personality disorder: a review of the evidence. Ann Clin Psychiatry 2014;26:139-44.

11. Wahid N, Chin G, Turner AH, Seegan A. Clinical response of clozapine as treatment for delirious mania. Ment Illn 2017;9:7182.

12. Meltzer HY. Clozapine: balancing safety with superior antipsychotic efficacy. Clin Schizophr Relat Psychoses 2012;6:134-44. 